\title{
Enzalutamide Regimen
}

National Cancer Institute

\section{Source}

National Cancer Institute. Enzalutamide Regimen. NCI Thesaurus. Code C160028.

A chemotherapy regimen consisting of enzalutamide that may be used in the treatment of prostate cancer. 